\title{
History, poetry and therapeutic alliance
}

That I wanted good poetry without knowing it,

That I discovered, late, its salutary aim, In this and only this I find salvation

—Czeslaw Milosz, "Dedication," 1945

To take a patient's history is often to discover world history.

$\mathrm{He}$ is one of the first patients I see at the family medicine centre, during the first week of July, at the very beginning of my residency. Old, crumpled, bent forward, walking slowly, wearing a pink waistcoat, a turquoise suit and a bow tie. I am scared of him because of the letters of his name - crowded with SZs and Xs and WLs - and because of the letters of his problem list: DMII, PVD, CAD, Afib, CHF, COPD, CRF. I feel uncomfortable calling his name in the waiting room, having no clue how to say it. I am relieved that he does not look as bad as his problem list. He speaks to me in Britishaccented English. I ask for the correct pronunciation of his name. Polish, I ask? Yes, from Warsaw. In Montréal since I955. He's been a Canadian since well before I was born. I look at the last notes in the chart, from the resident whose practice I am taking over. Blood

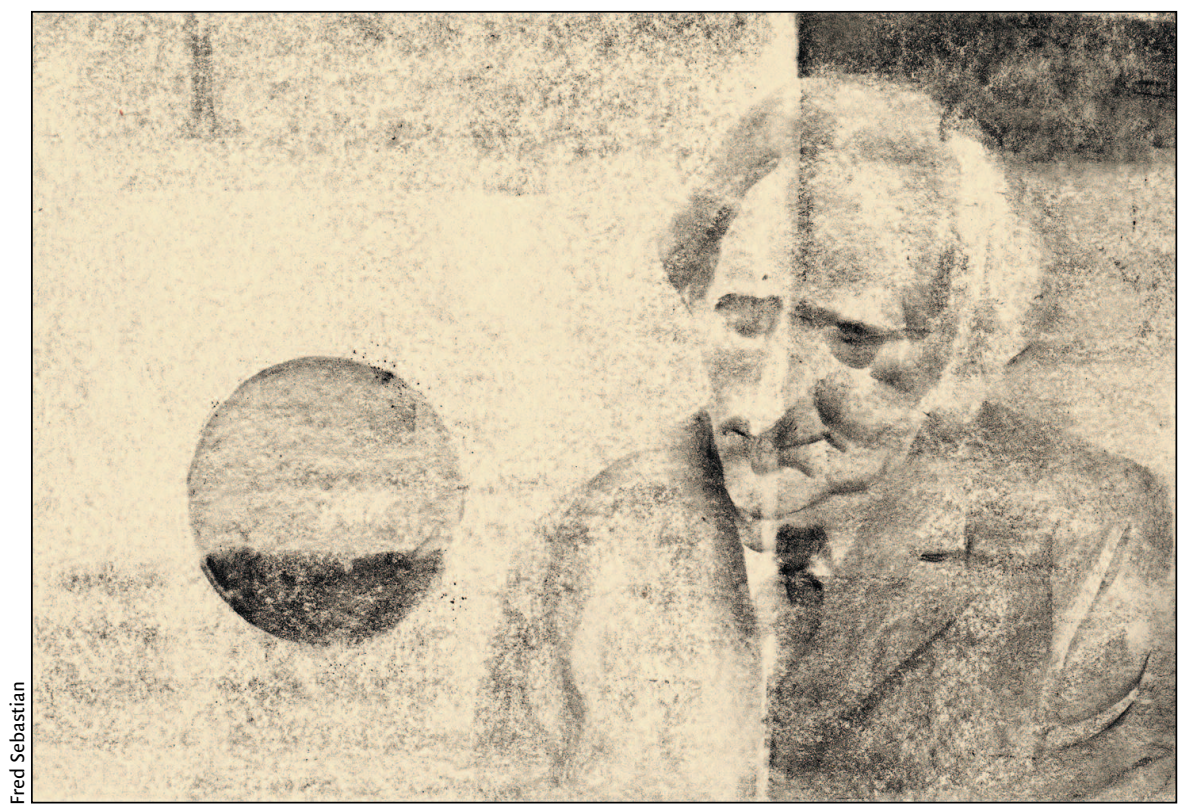

you," he says in a precise, Parisian-like French.

Blood pressure still shooting high. Long discussion about compliance issues and the intertwined risks of renal failure and hypertension. We agree on using a dosette, and that he should bring it at the next visit, in three months.

\section{I am scared of him because of the} letters of his name and because of the letters of his problem list.

pressure shooting up on three medications and a worsening kidney condition. "Compliance issues." His blood pressure is high, but this is a first contact. I renew his medications and ask him to bring them in their bottles to show me on his next visit.

\section{Second visit}

"Leblanc, is that a French name?"

"Of course," I laugh.

"Oh, then I'd better practise with
Third visit

He begins in English. "Doctor, I have a favour to ask. I need a certificate of good health."

"Good health, why?"

"I must go to Warsaw. There is a very important anniversary coming up."

I think back to his chart. Anniversary? His only family is a son in Montréal. And as far as good health is concerned, I don't think he qualifies.

"What anniversary?"
"The Warsaw uprising. There is a commemoration of the 6oth anniversary and I want to see who among my companions survived ..." - he switches to French in mid-sentence "and then go to Paris to meet my friends from the Résistance."

Touched, I look at this frail gentleman in a butter-yellow suit, who already looks a little less bent, a little less fragile. I shudder to think of the risk of deep-vein thrombosis on the plane, of increased oxygen requirements, of fatigue and dietary excess. But who am I to prevent him from going through this historical journey? What are these risks compared to those he took sixty years ago? After consulting with my supervisor, I come back and discuss the risks of travel, the need to stick to his diet as much as possible, to take his medications. As I talk about the importance of moving around on the plane, I realize he isn't listening to a word. He raises an eyebrow.

"You didn't ask what the Warsaw uprising was."

"Oh, well, I kind of know ..."

"Any special interest in Poland?" he says, winking. Back to English. Why am I blushing?

"No. Or maybe. One of my favourite poets is Polish." 
"Who is that?"

"Czeslaw Milosz"

"Oh really," he says, more animated than I've ever seen him. "Do you read him in French or in English?"

"Mostly in English. French translations of my favourites poems are hard to find."

"Then you must learn Polish."

"Maybe I will," I laugh, a bit uncomfortable.

He carries on, telling me about his guard duties during the uprising, of his friends who had been killed or betrayed, of his fears and doubts, of how hindsight has 20/20 vision. At the end of the interview, once again, I go over his medications and the importance of using them. Then I wish him a safe journey.

Fourth visit

It is December. I go to the waiting room to get my patient, who is wear- ing a red waistcoat and green jacket. He walks briskly into my office, sits down, and starts telling me how nice it felt to be back in Warsaw, to see his old friends, to at last be recognized by his people. "They treated me like a hero," he says. "You are a hero," I think. He is sitting straighter, looking healthier. His blood pressure is within limit. I ask to see his medication bottles; for the first time, he has them. The dosette has almost the right amount of empty squares. He looks well. He wishes me Merry Christmas. I encourage him to continue his medications, and we book an appointment for three to four months' time.

After my patient leaves I see a folded sheet of paper on my desk. I open it. It is a poem, written in blue ink in a looped and curving script that looks European to my eyes. "'Dedication,' by Czeslaw Milosz, translated for Dr. Leblanc by ..." this patient with

an alphabet soup of a name and a problem list even more challenging to decipher.

The translation is beautiful.

Fifth visit

My patient has come back. He is asking for my blessing for another trip, to Rome this time.

"The priest who celebrated my marriage just passed away in Rome. It was Karol Wotjila. He was from the neighbouring town. I have to go to his funeral."

\section{Isabelle Leblanc}

Second-year Resident

Department of Family Medicine

St. Mary's Hospital

McGill University

Montréal, Que.

\section{One thousand words}

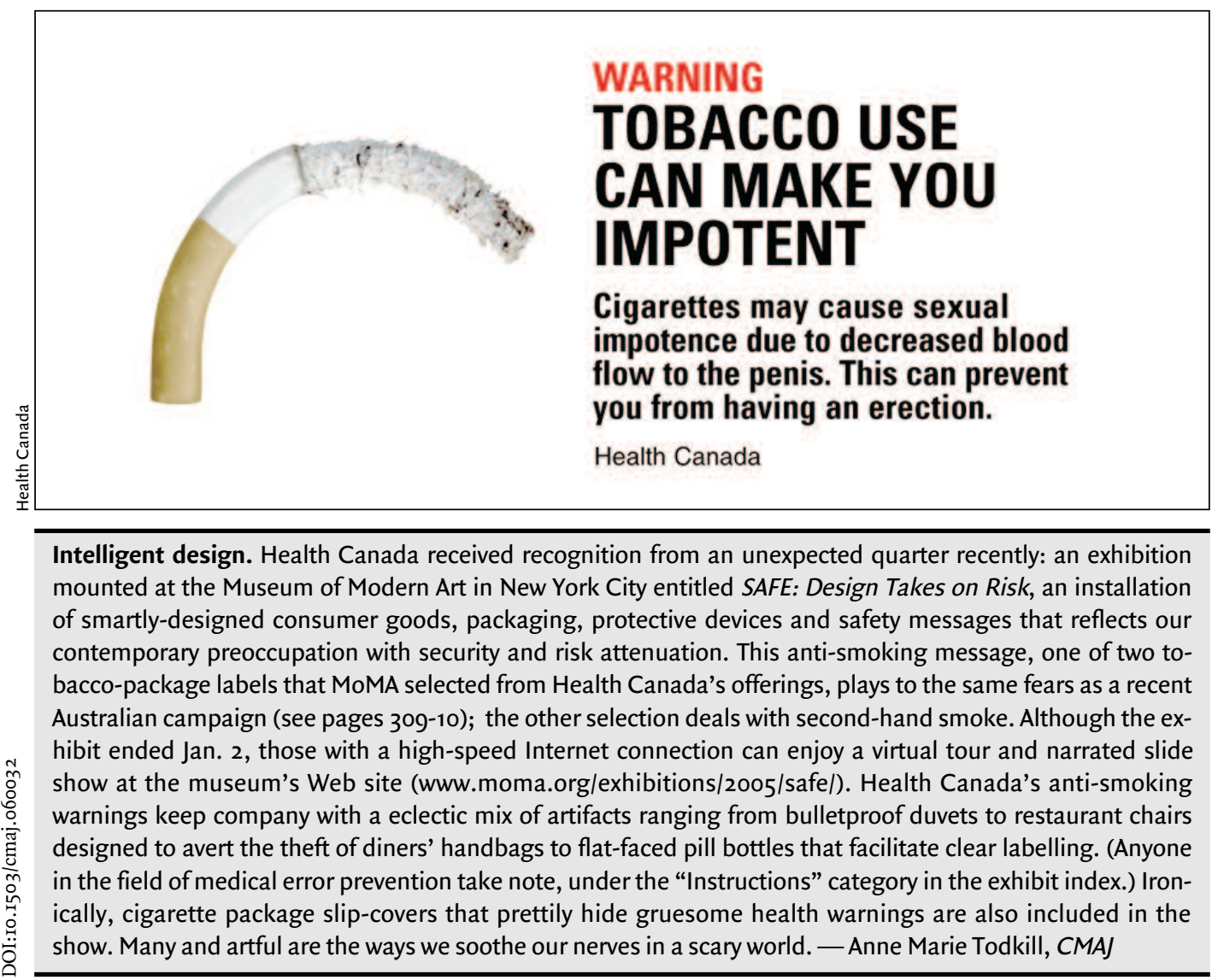

